\title{
NeuroRegulation
}

\section{Proceedings of the 2016 ISNR Conference: Plenary Presentations}

\author{
Selected Abstracts of Conference Presentations at the 2016 International Society for Neurofeedback \\ and Research (ISNR) 24th Conference, Orlando, Florida, USA
}

Citation: International Society for Neurofeedback and Research. (2016). Proceedings of the 2016 ISNR Conference: Plenary Presentations. NeuroRegulation, 3(4), 170-185. http://dx.doi.org/10.15540/nr.3.4.170

Copyright: ( ) 2016. ISNR. This is an Open Access article distributed under the terms of the Creative Commons Attribution License (CC-BY).

\section{Be CALM \& Pay ATTENTION! An Overview of Assessment Findings and Intervention Strategies for Attention-Deficit/Hyperactivity Disorder (ADHD) \\ Lynda Thompson and Michael Thompson \\ ADD Centre and Biofeedback Institute of Toronto, Mississauga, Ontario, Canada}

Participants will learn about diagnosis and intervention. Diagnosis will cover both a brief overview of DSM-5 criteria for both Inattentive and Combined presentations of AttentionDeficit/Hyperactivity Disorder (ADHD) and also mention of comorbidities. An explication of how adding additional measures from single-channel EEG data collection and administration of continuous performance tests supports the diagnosis. The salient areas to be covered during the clinical interview will also be covered; namely, the person's strengths, family matters (with mention of Judith Lubar's use of genograms), social functioning, school and/or work performance, medical factors (allergies, sleep apnea, head injuries, etc.), and extracurricular interests. Data from questionnaires and, for more objective test data, continuous performance tests (Test of Variables of Attention [T.O.V.A.] and Integrated Auditory and Visual Continuous Performance Test [IVA]) will be shown. The various patterns found on single-channel $(\mathrm{Cz})$ EEG assessment will be discussed in the light of the published norms for theta/beta power ratios. EEG patterns (excess theta, excess alpha, spindling beta, all seen with single channel assessment) will be shown. Recent updates on the utility of theta/beta as a marker for ADHD will be shared. Patients who have a diagnosis of ADHD symptoms can vary from children with a relatively simple difficulty with attention span to patients who have a complex array of other difficulties and comorbidities that involve other networks, such as learning disabilities, Asperger's syndrome, autism spectrum disorders, affect disorders, and movement disorders, including Tourette syndrome. This will be acknowledged but not expanded upon in this presentation. Finally, intervention will be discussed with mention of diet, sleep, and exercise but with the main focus being on how to do effective neurofeedback intervention combined with biofeedback with this population. Finally, there will be mention of research that addresses the question of whether neurofeedback can be considered an efficacious treatment for ADHD.

\section{References}

Arns, M., de Ridder, S., Strehl, U., Breteler, M., \& Coenen, A. (2009). Efficacy of neurofeedback treatment in ADHD: The effects on inattention, impulsivity and hyperactivity: A metaanalysis. Clinical EEG and Neuroscience, 40(3), 180-189. http://dx.doi.org/10.1177/155005940904000311

Lubar, J. F., \& Lubar, J. O. (1999). Neurofeedback assessment and treatment for Attention Deficit/Hyperactivity Disorders. In J. R. Evans \& A. Abarbanel, Introduction to Quantitative EEG and Neurofeedback. San Diego, CA: Academic Press.

Monastra, V. J., Lubar, J. F., Linden, M., VanDeusen, P., Green, G., Wing, W., ... Fenger, T. N. (1999). Assessing attention deficit hyperactivity disorder via quantitative electroencephalography: An initial validation study. Neuropsychology, 13(3), 424-433.

Santhirasegaram, L., Thompson, L., Reid, A., Thompson, M. (2013). Training for success in a child with ADHD. Biofeedback, 41(2), 75-81. http://dx.doi.org/10.5298/1081 5937-41.2.07

Sears, W., \& Thompson, L. (1998). The A.D.D. Book: New Understandings, New Approaches to Parenting Your Child. New York, NY: Little, Brown \& Co.

Thompson, L., \& Thompson, M. (1998). Neurofeedback combined with training in metacognitive strategies: Effectiveness in students with ADD. Applied Psychophysiology and Biofeedback, 23(4), 243-263. http://dx.doi.org/ 10.1023/A:1022213731956

Thompson, M., \& Thompson, L. (2015). The Neurofeedback Book: An Introduction to Basic Concepts in Applied Psychophysiology (2nd ed.). Wheat Ridge, CO: Association for Applied Psychophysiology and Biofeedback. 
Words that Don't Work: Frontal Gamma

Asymmetry Examination of Precognitive

Responses

Ronald Bonnstetter ${ }^{1}$ and Nancy Wigton ${ }^{2}$

${ }^{1}$ Target Training International, Scottsdale, Arizona, USA

${ }^{2}$ Applied Neurotherapy Center, LLC, Scottsdale, Arizona, USA

Objective. The purpose of this study was to explore the concept behind Newberg and Waldman's 2012 book, Words Can Change Your Brain, by capturing brain activation while being confronted with words that have been previously identified as correlating to specific behavioral typologies. The null hypothesis was that these "trigger words" would have the same reaction no matter what behavioral group was being tested.

Methods. The first step was for participants to take a behavioral assessment, known as Target Training International, Ltd. (TTI) Style Insights (Bonnstetter, 2014). This well-researched assessment has consistently shown that behavioral characteristics can be grouped together into four quadrants, or styles. The acronym DISC stands for: $D=$ Dominance, $I=$ Influence, $S=$ Steadiness and $C=$ Compliance. This instrument is based on William Moulton Marston's Emotions of Normal People. As stated by Marston, "All people exhibit all four behavioral factors in varying degrees of intensity." Therefore, each behavioral factor may be exhibited along a continuum from high to low, thus creating eight extremes. Participants exhibiting each of the DISC extremes underwent an EEG recording in our lab, while observing key behavioral terms. Prior to the initiation of the EEG recording, the subjects' primary behavioral style was noted. During the EEG data collection session, each subject was exposed to words previously established as words that elicit a negative reaction in a person of a certain primary style. Observations of gamma brain activity in the frontal cortex were classified as depicting acceptance, avoidance, or a neutral symmetry. Gamma is the primary focus of our measurements as it provides an immediate emotional response to a stimulus, even before a conscious thought has formed.

Results. Where avoidance to a word was observed, there was a greater amount of gamma activation in the right prefrontal lobe as opposed to the left.

Conclusions. Analyzing the data through the lens of DISC, it was observed that those with primary styles of Dominance and Compliance demonstrated significantly more avoidance than those with the Influence and Steadiness behavioral styles.
Subjects with a primary Dominance style had the most favorable responses to their own terms, but were more critical than all other styles on all other words. Dominance behavioral style also had the most intense bursts of activation and avoidance. Subjects with an Influence behavioral style had the most varied and inconsistent responses. Overall, they were the most forgiving by not having many strong negative reactions. Subjects with a Steadiness behavioral style demonstrated the least amount of avoidance and very little change in activation. Overall, they were most critical of some Steadiness words and some Dominance words. Subjects with a Compliance behavioral style had the most avoidance of all groups, even to their own descriptive terms.

Significance. Certain words not only cause a sudden negative response in conversation, but work at a neurological level to alter brain patterns and obstruct communication. Given the intensity and duration of these reactions, these trigger words have the potential to build or break a relationship. Trigger words can set the tone for the conversation and for the outcome of conversations.

\section{References}

Bonnstetter, B. J., \& Suiter, J. I. (2014) The Universal Language DISC (15th ed.). Scottsdale, AZ: Target Training International.

Bonnstetter, R. J., Hebets, D., \& Wigton, N. L. (2015). Frontal gamma asymmetry in response to soft skills stimuli: A pilot study. NeuroRegulation, 2(2), 70-85. http://dx.doi.org $/ 10.15540 / \mathrm{nr} .2 .2 .70$

Collura, T. F, Bonnstetter, R. J., \& Zalaquett, C. (2014). Seeing inside the client's mind. Counseling Today, 57(6), 24-27.

Collura, T. F., Wigton, N. L., Zalaquett, C., Chatters-Smith, S. S., \& Bonnstetter, R. J. (2016). The value of EEG-based electromagnetic tomographic analysis in human performance and mental health. Biofeedback, 44(2), 58-65. http://dx.doi.org/10.5298/1081-5937-44.2.03

Collura, T. F, Zalaquett, C. P., Bonnstetter, R. J., \& Chatters, S. J. (2014). Toward an operational model of decision-making, emotional regulation, and mental health impact. Advances in Mind-Body Medicine, 28(4), 18-33.

Davidson, R. J., Ekman, P., Saron, C. D., Senulis, J. A., \& Friesen, W. V. (1990) Approach-withdrawal and cerebral asymmetry: Emotional expression and brain physiology. Journal of Personality and Social Psychology, 58(2), 330341. http://dx.doi.org/10.1037/0022-3514.58.2.330

Newberg, A., \& Waldman, M. R. (2012). Words Can Change Your Brain: 12 Conversation Strategies to Build Trust, Resolve Conflict, and Increase Intimacy. New York, NY: Hudson Street Press. 
Getting to Know LORETA: Evaluating and Training Surface and Internal Brain Structures Joel Lubar

Southeastern Neurofeedback Inst., Pompano Beach, Florida, USA

In this presentation, I will present the groundwork for the development of LORETA which was first developed at the Key Institute in Zürich, Switzerland, by Roberto Pascal Marqui and Dietrich Lehman in 1994. LORETA allows one to visualize as many as 6,239 areas of the cortex and other regions including the hippocampus, the amygdala, the cingulate gyrus, and other areas where there are sufficient pyramidal cell generators. These areas that contain pyramidal cells are divided into three-dimensional cubes known as voxels. These cubes can be either $7 \times 7 \mathrm{~mm}$ or $5 \times 5 \mathrm{~mm}$ and comprise almost $70 \%$ of all the areas in the brain. I will discuss and illustrate how LORETA neurofeedback protocols are developed for more than 150 clinical disorders for which there is sufficient literature to support its application. I will then discuss the clinical application of LORETA neurofeedback with illustrations from cases of its effectiveness. These cases will cover the areas of depression, addiction disorders, and seizure disorders. LORETA neurofeedback complements and contrasts with fMRI neurofeedback. LORETA neurofeedback can train both specific regions of interest as well as the connection metrics between these regions of interest. These metrics include coherence, phase, phase shift, and phase lock and measures of effective connectivity which deal with the direction of flow of information from one brain region to another. This presentation will be at the elementary level for the new ISNR-lite format. Since this is an introductory presentation regarding LORETA which is a complex area I would like to have enough time to answer questions from the audience or to clarify anything which is not completely clear. If there is time, I would also like to mention graph theory since it allows the ability to visualize complex brain networks. There is now an extensive literature showing how these complex brain networks are linked to specific clinical entities. Examples of this are networks correlated with IQ, executive function, and many others.

\section{References}

Cannon, R., Lubar, J. F., Thornton, K., Wilson, S., \& Congedo, M. (2004). Limbic beta activation and LORETA: Can hippocampal and related limbic activity be recorded and changes visualized using LORETA in an affective memory condition? Journal of Neurotherapy, 8(4), 5-24. http://dx.doi.org/10.1300/J184v08n04_02
Lubar, J. F. (2003). Neurofeedback for the management of attention-deficit/hyperactivity disorders. In M. S. Schwartz \& F. Andrasik (Eds.), Biofeedback: A Practitioner's Guide (3rd ed., pp. 409-437). New York, NY: Guilford Publishing Co.

Lubar, J. F., Congedo, M., \& Askew, J. H. (2003). Low-resolution electromagnetic tomography (LORETA) of cerebral activity in chronic depressive disorder. International Journal of Psychophysiology, 49(3), 175-185. http://dx.doi.org/10.1016 IS0167-8760(03)00115-6

Thatcher, R. W., \& Lubar, J. F. (2014). Z-Score Neurofeedback: Clinical Applications. San Diego, CA: Academic Press.

\section{Comparing Bivariate and Multivariate Coherence Neurofeedback for Autism Spectrum Disorder \\ Morgan Middlebrooks and Robert Coben}

Integrated Neuroscience Services, Fayetteville, Arkansas, USA

Autism spectrum disorder (ASD) can be described as a "group of developmental disabilities that can cause significant social, communication, and behavioral challenges." The epidemiological data presented by the CDC reported that 1 in 68 children are currently diagnosed with ASD (CDC, 2016). The CDC has noted an increase in the prevalence of ASD since the 1990s, making effective treatment an important part of the conversation. Neurofeedback therapy has been shown to be an effective treatment for ASD, specifically two-channel neurofeedback therapy (NFB). A review of data of 150 clients with ASD showed that neurofeedback therapy can be appreciated as a viable treatment for those on the spectrum (Thompson, Thompson, \& Reid, 2009). Research by Coben and others has shown that while two-channel NFB has been an important step in our understanding of NFB, there are many problems with using a two-channel modality. $\mathrm{He}$ asserts that four-channel multivariate coherence training provides advantages over the more widely used two-channel treatment (Coben, 2014). Our study aims to provide empirical evidence of the advantages of four-channel multivariate coherence NFB by comparing two groups of patients who have been diagnosed on the ASD spectrum.

Methods. A total of 80 children on the autistic spectrum were assigned to two treatment groups inclusive of two-channel coherence and four-channel multivariate coherence training groups. Changes in power and coherence and autistic symptoms generally and various aspects of social skills will serve as the dependent variables. We will create a session score that appreciates coherence changes globally per session. Analysis will include the use of SPSS software for a MANOVA analysis. It will also include the use of NRep software suite to measure global changes in power and coherence. 
Assessments. Quantitative electroencephalogram studies were performed pre- and posttreatment, followed by parent report measures of the Social Responsiveness Scale-Second Edition (SRS-2; Constantino \& Gruber, 2012) and Autism Treatment Evaluation Checklist (ATEC), a parent-rated scale (Rimland \& Edelson, 1999). QEEG data was then analyzed with the NeuroRep software suite. ASD symptomology will be rated using the ATEC and parent rated social skills will be appreciated using the SRS-2.

Results. Results evaluating changes in global coherence and power measures in addition to changes in ASD symptoms, parent-rated social skills, and other aspects of ASD are anticipated to support our hypothesis that four-channel multivariate coherence training helps to improve coherence in the brain more efficiently than the more commonly used two-channel bivariate coherence training.

Discussion/Conclusion. Using the information from the above study we hope to add to the growing knowledge base regarding the use of neurofeedback therapy to help reduce symptoms in individuals with ASD.

\section{References}

Centers for Disease Control and Prevention. (2016). Autism spectrum disorder. Retrieved from http://www.cdc.gov/ncbddd lautism/index.html

Coben, R. (2014). Four Channel Multivariate Coherence Training: A New form of Neurofeedback. Presented at the 22nd Annual ISNR Conference, San Diego, CA.

Coben, R., Sherlin, L., Hudspeth, W. J., McKeon, K., \& Ricca, R. (2014). Connectivity-guided EEG biofeedback for autism spectrum disorder: Evidence of neurophysiological changes. NeuroRegulation, 1(2), 109-130. http://dx.doi.org/10.15540 /nr.1.2.109

Constantino, J. N., \& Gruber, C. P. (2012). Social Responsiveness Scale (2nd ed.). Los Angeles, CA: Western Psychological Services.

Kouijzer, M. E. J., de Moor, J. M. H., Gerrits, B. J. L., Congedo, M., \& van Schie, H. T. (2009). Neurofeedback improves executive functioning in children with autism spectrum disorders. Research in Autism Spectrum Disorders, 3(1), 145-162. http://dx.doi.org/10.1016/j.rasd.2008.05.001

Rimland, B., \& Edelson, M. (1999). Autism Treatment Evaluation Checklist. Autism Research Institute. 4812 Adams Avenue, San Diego, CA 92116. Retrieved from https://www.autismeval.com/ari-atec/report1.html

Thompson, L., Thompson, M., \& Reid, A. (2009). Neurofeedback outcomes in clients with Asperger's syndrome. Applied Psychophysiology and Biofeedback, 35(1), 63-81. http://dx.doi.org/10.1007/s10484-009-9120-3
NFB for Optimal Performance and Sport

Leslie Sherlin

Nova Tech EEG, Inc., Mesa, Arizona, USA

Largely in the past, athletic performance has been focused on training the body from an anatomical and muscular performance approach. As understanding and technology have emerged, the focus has broadened from simply being exercise physiology to true sports performance science that includes physiology, psychology, biomechanics, and nutrition. The term brain training is not an unfamiliar term but its definition and application are as diverse as the users. Quantitative electroencephalography (qEEG) and biofeedback modalities have been well established over the past 40 years to reflect and provide operant conditioning to the levels of cognitive engagement and arousal. An athlete who can exercise volitional control of these aspects of brain and body state has a supreme advantage during competition. This concept has received resistance and underutilization because research has spanned the observed, imagined, and performance of specific skills; however, to date the ideal mental states of performance and specific outcomes on performance has eluded investigators. The reinvention of brain wave technologies that is both practical to implement by not requiring a laboratory setting or advanced technical training for use has allowed us to build upon the previous years of research in brain electrophysiology and theory. Measuring the elite athlete brain has provided significant understanding of processes that now can be applied in a training tool that is both practical and effective to be implemented across a wide variety of sport performance settings for all skill levels. Some of these outcomes and experiences will be shared with practical information to be utilized in conducting sessions in this population.

\section{References}

Arns, M., Kleinnijenhuis, M., Fallahpour, K., \& Breteler, R. (2008). Golf performance enhancement and real-life neurofeedback' training using personalized event-locked EEG profiles. Journal of Neurotherapy, 11(4), 11-18. http://dx.doi.org /10.1080/10874200802149656

Badcock, N. A., Mousikou, P., Mahajan, Y., de Lissa, P., Johnson, T., \& McArthur, G. (2013). Validation of the Emotiv EPOC® EEG gaming system for measuring research quality auditory ERPs. PeerJ, 1(e38). http://dx.doi.org/10.7717/peerj.38

Baumeister, J., Reinecke, K., Liesen, H., \& Weiss, M. (2008). Cortical activity of skilled performance in a complex sports related motor task. European Journal of Applied Physiology, 104(4), 625-631. http://dx.doi.org/10.1007/s00421-008-0811$x$

Beauchamp, M. K., Harvey, R. H., \& Beauchamp, P.H. (2012). An integrated biofeedback and psychological skills training program for Canada's Olympic short-track speedskating team. Journal of Clinical Sport Psychology, 6, 67-84. 
Blumenstein, B., Bar-Eli, M., \& Collins, D. (2002). Biofeedback training in sport. In B. Blumenstein, M. Bar-Eli, \& G. Tenenbaum (Eds.), Brain and body in sport and exercise: Biofeedback applications in performance enhancement (pp. 55-76). Chichester, UK: Wiley.

Blumenstein, B., Bar-Eli, M., \& Tenenbaum, G. (Eds.). (2002). Brain and body in sport and exercise: Biofeedback applications in performance enhancement. Chichester, UK: Wiley.

Cochran, S. D. (2011). Corporate Peak Performance Project. Biofeedback, 39(3), 123-126.

Deeny, S. P., Haufler, A. J., Saffer, M., \& Hatfield, B. D. (2009). Electroencephalographic coherence during visuomotor performance: A comparison of cortico-cortical communication in experts and novices. Journal of Motor Behavior, 41(2), 106-116. http://dx.doi.org/10.3200/JMBR.41.2.106-116

Deeny, S. P., Hillman, C. H., Janelle, C. M., \& Hatfield, B. D. (2003). Cortico-cortical communication and superior performance in skilled marksmen: An EEG coherence analysis. Journal of Sport \& Exercise Psychology, 25, 188204.

Egner, T., \& Gruzelier, J. H. (2001). Learned self-regulation of EEG frequency components affects attention and eventrelated brain potentials in humans. NeuroReport, 12(18), $4155-4160$.

Gould, D., \& Udry, E. (1994). Psychological skills for enhancing performance: Arousal regulation strategies. Medicine and Science in Sports and Exercise, 26(4), 478-485.

Gruzelier, J. (2009). A theory of alpha/theta neurofeedback, creative performance enhancement, long distance functional connectivity and psychological integration. Cognitive Processing, 10(Suppl. 1), S101-S109. http://dx.doi.org /10.1007/s10339-008-0248-5

Gruzelier, J. H. (2013). EEG-neurofeedback for optimizing performance II: A review of creativity. Neuroscience \& Biobehavioral Reviews (in preparation, SAN special issue, Applied Neuroscience).

Gruzelier, J. H. (2014). EEG-neurofeedback for optimizing performance. I: a review of cognitive and affective outcome in healthy participants. Neuroscience \& Biobehavioral Reviews, 44, 124-141. http://dx.doi.org/10.1016 /j.neubiorev.2013.09.015

Gruzelier, J., \& Egner, T. (2005). Critical validation studies of neurofeedback. Child \& Adolescent Psychiatric Clinics of North America, 14(1), 83-104. http://dx.doi.org/ 10.1016/j.chc.2004.07.002

Gruzelier, J. H., Thompson, T., Redding, E., Brandt, R., \& Steffert, T. (2014). Application of alpha/theta neurofeedback and heart rate variability training to young contemporary dancers: State anxiety and creativity. International Journal of Psychophysiology, 93(1), 105-111. http://dx.doi.org/ 10.1016/j.jpsycho.2013.05.004

Shaw, L., Wilson, V., \& Nihon, S. (2012). Getting off the bench: EEG and HRV differences between starters and nonstarters. Biofeedback, 40(1), 34-38. http://dx.doi.org/10.5298/10815937-40.1.5

Sherlin, L. H., Arns, M., Lubar, J., Heinrich, H., Kerson, C., Strehl, U., \& Sterman, B. (2011). Neurofeedback and basic learning theory: Implications for research and practice. Journal of Neurotherapy, 15(4), 292-304. http://dx.doi.org/10.1080 /10874208.2011.623089

Sherlin, L., \& Larson Ford, N. C. (In Press). Biofeedback and neurofeedback in enhancing performance: Level 3, probably efficacious. In G. Tan, F. Shaffer, R. Lyle, \& I. Teo, EvidenceBased Practice in Biofeedback and Neurofeedback. Wheat Ridge, CO: AAPB.

Sherlin, L. H., Ford, N., Baker, A. R., \& Troesch, J. (2015). Observational report of the effects of performance brain training in collegiate golfers. Biofeedback, 43(2), 64-72. http://dx.doi.org/10.5298/1081-5937-43.2.06
Srinivasan, N. S. (2011). Enhancing neuroplasticity to improve peak performance. Biofeedback, 40(1), 30-33. http://dx.doi.org/10.5298/1081-5937-40.1.2

\section{Relative Efficacy of Two Different Forms of Coherence Neurofeedback for Seizure Disorders \\ Morgan Middlebrooks, Robert Coben, and Janease Traylor \\ Integrated Neuroscience Services, Fayetteville, Arkansas, USA}

The CDC describes epilepsy as an umbrella term for a brain disorder that causes seizures. The CDC estimates that nearly $1.8 \%$ of adults and $1 \%$ of children have had a diagnosis of epilepsy or seizure disorder (CDC, 2016). Many of those diagnosed with a seizure disorder are resistant to pharmaceutical intervention, which poses a need for alternative forms of treatment. Drug-resistant seizures are called many things (refractory, uncontrolled, intractable, etc.), but the International League Against Epilepsy defines drug-resistant epilepsy as occurring when a person has failed to stay seizure-free with adequate trials of at least two appropriate seizure medications. Most reports agree that drug-resistant epilepsy occurs in about one-third of the epileptic population (Sirven \& Shafer, 2014). High prevalence rates of epilepsy have led researchers to seek understanding of the neurological underpinnings of the disorder using a range of measures including EEG, MEG, and MRI connectivity. Coben and Mohammad-Rezazadeh (2015) have shown that the use of Granger causality with EEG data can help determine the source foci of these ictal events and related connectivity patterns. In a review of the scientific literature, a metaanalysis of neurofeedback treatment with epilepsy resulted in 10 studies that reported overall mean decreases in seizure incidence following treatment for 64 of 87 patients (Tan et al., 2002). Using the information obtained with qEEG and Granger causality to guide neurofeedback, we hope to provide examples of the benefits of four-channel multivariate coherence training to the epileptic population. Neurofeedback therapy has traditionally centered on a one- or two-channel approach, but we hypothesize that using four-channel multivariate coherence neurofeedback therapy will enhance outcomes with seizure disorders.

Methods. A total of 60 individuals diagnosed with seizure disorder were assigned to two treatment groups inclusive of two-channel coherence and fourchannel multivariate coherence training groups. Changes in coherence, power, seizure events and autistic symptoms will serve as the dependent 
variables. Analysis will include the use of SPSS software for MANOVA analysis. It will also include the use of NRep software suite to measure changes in coherence and power.

Assessments. Quantitative electroencephalogram studies were performed pre- and posttreatment. Dependent variables will be measured with the NeuroRep Compare program, Persyst II/Spike Detection software and ATEC (Rimland \& Edelson, 1999).

Results. Our initial findings using two-channel bivariate coherence neurofeedback reduced seizure events for those on or off meds. It also showed that patients who received the two-channel treatment and meds would see a diminishing of seizure events when the meds were removed. We hypothesize that four-channel multivariate coherence neurofeedback will have greater enhancements of coherence while also decreasing power and seizure events. It is further hypothesized that parent-rated autistic symptoms will show greater and more efficient reductions.

Discussion/Conclusion. Using the information from the above study we hope to add to the growing knowledge base regarding the use of neurofeedback therapy to help reduce the symptoms experienced by those diagnosed with seizure disorders.

\section{References}

Centers for Disease Control and Prevention. (2016). Epidemiologic, Population, and Health Outcome Studies of Epilepsy. Retrieved April 18, 2016, from http://www.cdc.gov/ncbddd/autism/index.html

Coben, R. (2013). Neural connectivity theory of Epilepsy. Presented at ISNR 21st Annual Conference in Dallas, TX.

Coben, R., \& Mohammad-Rezazadeh, I. (2015). Neural connectivity in epilepsy as measured by Granger causality. Frontiers in Human Neuroscience, 9, 194. http://doi.org/10.3389/fnhum.2015.00194

Rimland B., \& Edelson M. (1999). Autism Treatment Evaluation Checklist. Autism Research Institute. 4812 Adams Avenue, San Diego, CA 92116. Retrieved from https://www.autismeval.com/ari-atec/report1.html

Sirven, J. I., \& Shafer, P. O. (2014, March). Refractory Epilepsy. Retrieved April 18, 2016, Retrieved from http://www.epilepsy.com/learn/refractory-epilepsy

Tan, G., Thornby, J., Hammond, D. C., Strehl, U., Canady, B., Arnemann, K., \& Kaiser, D. A. (2002). Meta-analysis of EEG biofeedback in treating epilepsy. Clinical EEG and Neuroscience, 40(3), 173-179.

\section{Science and Clinical Application of}

Instantaneous Z-Score Neurofeedlback

Thomas Collura ${ }^{1}$ and Robert Thatcher ${ }^{2}$

${ }^{1}$ Brain Enrichment Center, Bedford, Ohio, USA

${ }^{2}$ Applied Neuroscience, Inc., Largo, Florida, USA

Objectives. The objectives are to explain and present the history, science, and clinical applications of instantaneous $z$-score neurofeedback (NFB). The two presenters will split time and present their different histories and different approaches to instantaneous $z$-score NFB. The topics will include the technical underpinnings of the computation of instantaneous $z$-scores using a reference database and clinical evidence that the proposed mechanism are supported by electrophysiological and outcome data. Special emphasis will be placed on scientific standards of instantaneous z-scores and comparisons to standard raw z-score NFB will be discussed. Both presenters will provide demonstrations of different methods of implementing z-score NFB.

History. Z-score NFB was first conceived and planned in 1999 for a new distribution of Lexicor, Inc. software. However, it was not until 2004 that Applied Neuroscience, Inc. completed the computer programming and developed a dynamic link library (DLL) for distribution that can be used by a wide number of different EEG amplifiers and software environments. In 2006 the ANI DLL was licensed to BrainMaster Technologies, Inc. and Thought Technology, LLC. From 2007 to 2010 the ANI instantaneous $z$-score DLL was also licensed to Deymed, Inc., EEG Spectrum, Mind Media, and Neurofield, Inc. The ANI z-score DLL is now used by over 3,000 clinicians located worldwide. In 2012, BrainDx, LLC developed a z-score DLL based on the NYU database, that is offered with BrainMaster; QEEG Professionals further developed a $z$-score DLL that is also offered by BrainMaster. The two presenters will show their respective software implementations and inventive ways to utilize instantaneous $z$-scores for NFB. Emphasis will be placed on the commonalities and differences between in the implementation of $z$-score NFB.

Clinical Applications. The clinical applications of $z-$ score NFB will be contrasted with "raw" score NFB, and the clinical literature will be explored and discussed. Z-score NFB only has a 10-year history but nonetheless has resulted in numerous publications and successes in obtaining in good clinical outcome in fewer sessions. There are four main advantages of $z$-score NFB: (1) Simplification where different EEG metrics are unified to a single 
metric, the metric of a z-score which is the distance the EEG measure is from an age-matched reference normal population, (2) elimination of guessing about what the threshold for NFB for a given metric or set of metrics should be set at, (3) efficiency by improved guidance with respect to a healthy reference population for all EEG metrics and, (4) physiological validity of simultaneously reinforcing multiple metrics toward increased stability in brain network hubs and connections between hubs.

\section{References}

Bauer, H., \& Pllana, A. (2014). EEG-based local brain activity feedback training-Tomographic neurofeedback. Frontiers in Human Neuroscience, 8, 1005. http://dx.doi.org/10.3389 /fnhum.2014.01005

Cannon, R. L., \& Baldwin, D. R. (2012). EEG current source density and the phenomenology of the default network. Clinical EEG and Neuroscience, 43(4), 257-267. http://dx.doi.org/10.1177 /1550059412449780

Cannon, R. L., Baldwin, D. R., Diloreto, D. J., Phillips, S. T., Shaw, T. L., \& Levy, J. J. (2014). LORETA neurofeedback in the precuneus: Operant conditioning in basic mechanisms of self-regulation. Clinical EEG and Neuroscience. Advance online publication. http://dx.doi.org/10.1177 $/ 1550059413512796$

Cannon, R. L., Baldwin, D. R., Shaw, T. L., Diloreto, D. J., Phillips, S. M., Scruggs, A. M., \& Riehl, T. C. (2012). Reliability of quantitative EEG (qEEG) measures and LORETA current source density at 30 days. Neuroscience Letters, $\quad 518(1), \quad 27-31 . \quad$ http://dx.doi.org/10.1016 /j.neulet.2012.04.035

Cannon, R., Congedo, M., Lubar, J., \& Hutchens, T. (2009). Differentiating a network of executive attention: LORETA neurofeedback in anterior cingulate and dorsolateral prefrontal cortices. International Journal of Neuroscience, 119(3), 404-441. http://dx.doi.org/10.1080 100207450802480325

Cannon, R., \& Lubar, J. F. (2008). EEG spectral power and coherence: Differentiating effects of Spatial-Specific NeuroOperant Learning (SSNOL) utilizing LORETA Neurofeedback training in the anterior cingulate and bilateral dorsolateral prefrontal cortices. Journal of Neurotherapy, 11(3), 25-44. http://dx.doi.org/10.1080/10874200802126191

Cannon, R., Lubar, J. F., Congedo, M., Gerke, A., Thornton, K., Kelsay, B., et al. (2006b, in press). The effects of neurofeedback training in the cognitive division of the anterior cingulate gyrus. International Journal of Neuroscience.

Cannon, R., Lubar, J., Gerke, A., Thornton, K., Hutchens, T., \& McCammon, V. (2006a). EEG spectral-power and coherence: LORETA neurofeedback training in the anterior cingulate gyrus. Journal of Neurotherapy, 10(1), 5-31.

Cannon, R., Lubar, J., Sokhadze, E., \& Baldwin, D. (2008). LORETA neurofeedback for addiction and the possible neurophysiology of psychological processes influenced: $A$ case study and region of interest analysis of LORETA neurofeedback in right anterior cingulate cortex. Journal of Neurotherapy, 12(4), 227-241.

Cannon, R., Lubar, J., Thornton, K., Wilson, S., \& Congedo, M. (2005). Limbic beta activation and LORETA: Can hippocampal and related limbic activity be recorded and changes visualized using LORETA in an affective memory condition? Journal of Neurotherapy, 8(4), 5-24.

Collura, T. F. (2008, April). Whole head normalization using live $z-$ scores for connectivity training, Part 1. NeuroConnections, $12,15,18-19$.
Collura, T. F. (2008, July). Whole head normalization using live zscores for connectivity training, Part 2. NeuroConnections, 912.

Collura, T. (2008). Time EEG z-score training: Realities and prospects. In J. Evans, L. Arbanel, \& T. Budsynsky, Quantitative EEG and Neurofeedback. San Diego, CA: Academic Press.

Collura, T. F. (2009, January). Practicing with multichannel EEG, DC, and slow cortical potentials. NeuroConnections, 35-39.

Collura, T., Guan, J., Tarrent, J., Bailey, J., \& Starr, R. (2010). EEG biofeedback case studies using live $z$-score training and a normative database. Journal of Neurotherapy, 14(1), 22-46.

Collura, T., Thatcher, R., Smith, M. L., Lambos, W., \& Stark, C. (2009). EEG biofeedback training using live z-scores and a normative database. Philadelphia, PA: Elsevier.

Congedo, M. (2003). Tomographic neurofeedback: A new technique for the self-regulation of brain electrical activity (Unpublished doctoral dissertation). University of Tennessee, Knoxville, TN

Congedo, M. (2006). Subspace projection filters for real-time brain electromagnetic imaging. IEEE Transactions on Biomedical Engineering, 53(8), 1624-1634. http://dx.doi.org /10.1109/TBME.2006.878055

Congedo, M., Lubar, J., \& Joffe, D. (2004a). Tomographic neurofeedback: A new technique for the self-regulation of brain electrical activity [Abstract]. Journal of Neurotherapy, $8(2), 141-142$.

Congedo, M., Lubar, J. F., \& Joffe, D. (2004b). Low-resolution electromagnetic tomography neurofeedback. IEEE Transactions on Neuronal Systems and Rehabilitation Engineering, 12(4), 387-397.

Decker, S. L., Roberts, A. M., \& Green, J. J. (2014). LORETA neurofeedback in college students with ADHD. In R. W. Thatcher \& J. F. Lubar, Z Score Neurofeedback: Clinical Applications. San Diego, CA: Academic Press.

Foster, D. S., \& Thatcher, R. W. (2014). Surface and LORETA neurofeedback in the treatment of post-traumatic stress disorder and mild traumatic brain injury. In R. W. Thatcher \& J. F. Lubar, Z Score Neurofeedback: Clinical Applications. San Diego, CA: Academic Press.

Gluck, G., \& Wand, P. (2014). LORETA and spec scans: A correlational case series. In R. W. Thatcher \& J. F. Lubar, Z Score Neurofeedback: Clinical Applications. San Diego, CA: Academic Press.

Hammer, B. U., Colbert, A. P., Brown, K. A., \& llioi, E. C. (2011). Neurofeedback for insomnia: A pilot study of z-score SMR and individualized protocols. Applied Psychophysiology and Biofeedback, 36(4), 251-264. http://dx.doi.org/10.1007 /s10484-011-9165-y.

Keeser, D., Kirsch, V., Rauchmann, B., et al. (2015). The impact of source-localized EEG phase neurofeedback on brain activity -A double blind placebo controlled study using simultaneously EEG-fMRI-. Manuscript submitted for publication.

Koberda, J. L. (2011). Clinical advantages of quantitative electroencephalogram (QEEG) application in general neurology practice. Neuroscience Letters, 500(Suppl.), e32.

Koberda, J. L. (2012). Autistic spectrum disorder (ASD) as a potential target of $z$-score LORETA neurofeedback. NeuroConnections, Winter 2012, 24-25.

Koberda, J. L. (2012). Comparison of the effectiveness of $z$-score surface/LORETA 19-electrode neurofeedback to standard 1electrode neurofeedback. Journal of Neurotherapy.

Koberda, J. L. (2014). QEEG/LORETA electrical imaging in neuropsychiatry diagnosis and treatment implications, Chapter 2. In V. Asher-Hansley (Ed.), Advances in Neuroimaging Research (pp 121-146). Nova Biomedical Publishing.

Koberda, J. L. (2014). LORETA z-score neurofeedback in chronic pain and headaches. In R. W. Thatcher \& J. F. Lubar, Z 
Score Neurofeedback: Clinical Applications. San Diego, CA: Academic Press.

Koberda, J. L. (2014). Neuromodulation-An emerging therapeutic modality in neurology. Journal of Neurology \& Stroke, 1(4), $00027 . \quad \mathrm{http} / / / \mathrm{dx}$. doi.org/10.15406 /jnsk.2014.01.00027

Koberda, J. L. (2014). Therapy of seizures and epilepsy with zscore LORETA neurofeedback. In R. W. Thatcher \& J. F. Lubar, Z Score Neurofeedback: Clinical Applications. San Diego, CA: Academic Press.

Koberda, J. L. (2014). Z-score LORETA neurofeedback as a potential therapy in depression/anxiety and cognitive dysfunction. In R. W. Thatcher \& J. F. Lubar, Z Score Neurofeedback: Clinical Applications. San Diego, CA: Academic Press.

Koberda, J. L. (2014). Z-score LORETA neurofeedback as a potential therapy in cognitive dysfunction and dementia. Journal of Psychology \& Clinical Psychiatry, 1(6), 00037. http://dx.doi.org/10.15406/jpcpy.2014.01.00037

Koberda, J. L. (2015). Application of z-score LORETA neurofeedback in therapy of epilepsy. Journal of Neurology and Neurobiology, 1(1). http://dx.doi.org/10.16966/23797150.e101

Koberda, J. L. (2015). LORETA z-score neurofeedbackeffectiveness in rehabilitation of patients suffering from traumatic brain injury. Journal of Neurology and Neurobiology, 1(4). http://dx.doi.org/10.16966/2379-7150.113

Koberda, J. L., \& Frey, L. C. (2015). Z-score LORETA neurofeedback as a potential therapy for patients with seizures and refractory epilepsy. Journal of Neurology and Neurobiology, 1(1), 1-6.

Koberda, J. L., Hillier, D. S., Jones, B., Moses, A., \& Koberda, L. (2012). Application of neurofeedback in general neurology practice. Journal of Neurotherapy, 16(3), 231-234. http://dx.doi.org/10.1080/10874208.2012.705770

Koberda, J. L., Koberda, P., Bienkiewicz, A. A., Moses, A., Koberda, L. (2013). Pain management using 19-electrode $z$ score LORETA neurofeedback. Journal of Neurotherapy, 17(3), 179-190. http://dx.doi.org/10.1080 /10874208.2013.813204

Koberda, J. L., Moses, A., Koberda, L., \& Koberda, P. (2012). Cognitive enhancement using 19-electrode z-score neurofeedback. Journal of Neurotherapy, 16(3), 224-230. http://dx.doi.org/10.1080/10874208.2012.705769

Koberda, J. L., Moses, A., Koberda, P., \& Bienkiewicz, A. A., \& Koberda, L. (2013). Alzheimer's dementia as a potential target of Z-score LORETA 19-electrode neurofeedback. NeuroConnections, Winter 2013, 30-32.

Koberda J, L., \& Stodolska-Koberda, U. (2014). Z-score LORETA neurofeedback as a potential rehabilitation modality in patients with CVA. Journal of Neurology \& Stroke, 1(5), 00029.

Krigbaum, G., \& Wigton, N. L. (2015). A methodology of analysis for monitoring treatment progression with 19-channel z-score neurofeedback (19ZNF) in a single-subject design. Applied Psychophysiology and Biofeedback, 40(3), 139-149. http://dx.doi.org/10.1007/s10484-015-9274-0

Lambos, W. A., \& Williams, R. A. (2014). Treating executive functioning disorders using LORETA $z$-scored EEG biofeedback. In R. W. Thatcher \& J. F. Lubar, Z Score Neurofeedback: Clinical Applications. San Diego, CA: Academic Press.

Little, R. M., Bendixsen, B. H., \& Abbey, R. D. (2014). 19 channel $z$-score training for learning disorders and executive functioning. In R. W. Thatcher \& J. F. Lubar, Z Score Neurofeedback: Clinical Applications. San Diego, CA: Academic Press.

Lubar, J. L. (2014). Optimal procedures in Z score neurofeedback: Strategies for maximizing learning for surface and LORETA Neurofeedback. In R. W. Thatcher \& J. F.
Lubar, Z Score Neurofeedback: Clinical Applications. San Diego, CA: Academic Press.

Lubar, J., Congedo, M., \& Askew, J. H. (2003). Low-resolution electromagnetic tomography (LORETA) of cerebral activity in chronic depressive disorder. International Journal of Psychophysiology, 49(3), 175-185.

Simkin, D. R., Thatcher, R. W., \& Lubar, J. (2014). Quantitative EEG and neurofeedback in children and adolescents: Anxiety disorders, depressive disorders, comorbid addiction and attention-deficit/hyperactivity disorder, and brain injury. Child \& Adolescent Psychiatric Clinics, 23(3), 427-464. http://dx.doi.org/10.1016/j.chc.2014.03.001

Smith, M. L. (2008, April). A father finds a solution: Z-score training. NeuroConnections, 22, 24-25.

Stark, C. R. (2008, April). Consistent dynamic Z-score patterns observed during Z-score training sessions - Robust among several clients and through time for each client. NeuroConnections, 37-38.

Surmeli, T., \& Ertem, A. (2009). QEEG guided neurofeedback therapy in personality disorders: 13 case studies. Clinical EEG and Neuroscience, 40(1), 5-10. http://dx.doi.org $/ 10.1177 / 155005940904000107$

Thatcher, R. W. (2000). 3-dimensional EEG biofeedback using LORETA. Eighth Annual Society for Neuronal Regulation, Minneapolis, MN, September 23, 2000.

Thatcher, R. W. (2010, December). LORETA Z score biofeedback. NeuroConnections, 9-13, 14-17.

Thatcher, R. W. (2012). Handbook of Quantitative Electroencephalography and EEG Biofeedback. St. Petersburg, FL: Anipublishing, Inc.

Thatcher, R. W. (2013). Latest developments in live z-score training: Symptom check list, phase reset, and Loreta $z$-score biofeedback. Journal of Neurotherapy, 17(1), 69-87. http://dx.doi.org/10.1080/10874208.2013.759032

Thatcher, R. W., North, D. M., \& Biver, C. J. (2014). BrainSurfer 3-dimensional Z score brain-computer-interface. In R. W. Thatcher \& J. F. Lubar, Z Score Neurofeedback: Clinical Applications. San Diego, CA: Academic Press.

Thatcher, R. W., North, D. M., \& Biver, C. J. (2014). Network connectivity and LORETA Z score NFB. In R. W. Thatcher \& J. F. Lubar, Z Score Neurofeedback: Clinical Applications. San Diego, CA: Academic Press.

Thatcher, R. W., North, D. M., \& Biver, C. J. (2014). Technical foundations of $Z$ score neurofeedback. In R. W. Thatcher \& J. F. Lubar, Z Score Neurofeedback: Clinical Applications. San Diego, CA: Academic Press.

Thompson, L., Thompson, M., \& Reid, A. (2010). Functional Neuroanatomy and the rationale for using EEG biofeedback for clients with Asperger's syndrome. Journal of Applied Psychophysiology and Biofeedback, 35(1), 39-61. http://dx.doi.org/10.1007/s10484-009-9095-0

Thompson, M., Thompson, L., \& Reid-Chung, A. (2014). Combining LORETA $z$-score neurofeedback with heart rate variability training. In R. W. Thatcher \& J. F. Lubar, Z Score Neurofeedback: Clinical Applications. San Diego, CA: Academic Press.

Wigton, N. L. (2013). Clinical perspectives of 19-channel z-score neurofeedback: Benefits and limitations. Journal of Neurotherapy, 17(4), 259-264. http://dx.doi.org/10.1080 /10874208.2013.847142

Wigton, N. L., \& Krigbaum, G. (2015). Attention, executive function, behavior, and electrocortical function, significantly improved with 19-channel z-score neurofeedback in a clinical setting: A pilot study. Journal of Attention Disorders. Advance online publication. http://dx.doi.org/10.1177 /1087054715577135 
Integrating Neurofeedback and

Photobiomodulation in the Treatment of

Neuropsychiatric Disorders and

Neurodegenerative Disease

Lew Lim ${ }^{1}$ and Marvin H. Berman

${ }^{1}$ Vielight Inc., Toronto, Ontario, Canada

${ }^{2}$ Quietmind Foundation, Plymouth Meeting, Pennsylvania, USA

The use of low levels of visible or NIR light for reducing pain, inflammation, and edema; promoting healing of wounds, deeper tissues, and nerves; and preventing tissue damage has been known for almost 40 years since the invention of lasers in the early 1960s (Karu, 1998). Despite many reports of positive findings from experiments conducted in vitro, in animal models, and in randomized controlled clinical trials, LLLT remains controversial. Karu (2008) has proposed that mitochondria are a likely site for the initial effects of light, specifically that the enzyme cytochrome $c$ oxidase (unit four in the mitochondrial respiratory chain) absorbs photons and increases its activity leading to increased ATP production, modulation of reactive oxygen species, and induction of transcription factors (Karu, 2008). The suggestion that cytochrome $c$ oxidase is the photoacceptor molecule was confirmed using functionally inactivated primary neurons, proposing that light upregulates this enzyme (Wong-Riley, 2005). More recent animal studies have demonstrated positive effects of brief red +NIR stimulation as comparable to SSRI in treating symptoms of anxiety and depression (Salehpour, Rasta, Mohaddes, Sadigh-Eteghad, \& Salarirad, 2016). Recent human clinical trials conducted at Quietmind Foundation have demonstrated that either neurofeedback training or repeated brief transcranial near infrared light stimulation can positive improvements in neuropsychiatric, neuropsychological, and qEEG measures. Clinical trials combining these two approaches are in the planning stages and anecdotal data from combining these interventions with patients in the clinic support their hypothesized synergistic potential (Berman, 2012; Berman \& Frederick, 2009). The impact of NIR stimulation was demonstrated during a live demonstration at ISNR last year using the Vielight Neuro $810 \mathrm{~nm}$ transcranial and intranasal unit. Initiating the stimulation at the Rich Club network locations (Fz, P3, Pz, P4) resulted in a rapid normalization of the volunteer subject's $z$-scores with subsequent reported improvement in TBI-related cognitive and motor planning symptoms. Lim had reported improvements in case studies of Alzheimer's patients using the Vielight 810 . He and his collaborators have also just completed a randomized, single-blind controlled pilot study, treating subjects with dementia with the Vielight devices. The results were significantly better (with no side effects) than those reported by the FDAapproved donepezil ("Aricept") by Pfizer in their clinical study. The workshop will present a model for integrated NIR+NFB therapy using clinical case series data of patients diagnosed with TBI on the combination of NIR stimulation using the Vielight Neuro technology. We further intend to provide a model using predictive analytics that can show the expected level of improvement from the combined LORETA z-score neurofeedback and NIR treatment. The study is now being conducted and will be completed August 2016. The combined intervention was demonstrated at ISNR 2015. NFB and NIR treatment have been studied separately and the predictive analytic component will be the only novel element in the study design and subsequent presentation. Sample size will be at least 10 subjects with diagnoses of memory loss with and/or without TBI. Subjects will be pretested using standard eyes open and closed qEEG, ADAS-cog neuropsychological assessment, and the IVA-2 visual and auditory continuous performance test.

\section{References}

Berman, M., \& Frederick, J. (July, 2009). Efficacy of Neurofeedback for executive and memory functioning dementia. Hot Topics section presentation at the International Conference on Alzheimer's Disease, Vienna, Austria.

Berman, M. (2012). Therapeutic effect of brief intensive nearinfrared light stimulation for cognitive and behavioral symptoms in dementia. Unpublished manuscript. Quietmind Foundation, Plymouth Meeting, PA.

Karu, T. I. (1988). Molecular mechanism of the therapeutic effect of low-intensity laser radiation. Lasers in the Life Sciences, 2(1), 53-74.

Karu, T. (2008). ACTION SPECTRA: Their Importance for Low Level Light Therapy. Retrieved from http://photobiology.info /Karu.html

Salehpour, F., Rasta, S., Mohaddes, G., Sadigh-Eteghad, S., \& Salarirad, S. (2016). Therapeutic Effects of $10-\mathrm{Hz}$ Pulsed Wave Lasers in Rat Depression Model: A Comparison between Near-Infrared and Red Wavelengths. Lasers in Surgery and Medicine, 48(7), 695-705. http://dx.doi.org /10.1002/lsm.22542

Wong-Riley, M. T. T., Liang, H. L., Eells, J. T., Chance, B., Henry, M. M., Buchmann, E., Kane, M., \& Whelan, H. T. (2005). Photobiomodulation directly benefits primary neurons functionally inactivated by toxins: Role of cytochrome c oxidase. Journal of Biological Chemistry, 280(6), 4761-4771. http://dx.doi.org/10.1074/jbc.M409650200 
Why Supplementation of the Functional Forms of Vitamin B12 May Be Helpful to Brain Health, Particularly for the Elderly, Under Conditions of Oxidative Stress and Inflammation

\section{Robert Boddington}

Private Researcher, New York, New York, USA

A recent major editorial in the Journal of Alzheimer's Disease signed by 33 senior scientists and clinicians concluded that diminished immune system competence in controlling common long-resident microbes was the most likely cause of Alzheimer's Disease (AD), and that amyloid beta plaque is, at least initially, only a defense mechanism (Itzhaki et al., 2016). This hypothesis is supported by a previous study reporting that levels of methylcobalamin (Methyl-B12), one of the two metabolically active or functional forms of Vitamin B12, was 12.4-fold lower in 61- to 80-year-old autopsied human prefrontal cortex than in 0 to 20year-olds and 6.7-fold lower than in 41- to 60-yearolds. A sharp fall-off was also reported in the oldest age group for adenosylcobalamin (Adeno-B12). Material lower levels for Methyl-B12 were also found in age-matched young autistic and middle-age schizophrenic subjects (Zhang et al., 2016). The implied connection: In addition to the important roles B12 has in the formation and maintenance of myelin sheath, protecting nerve function, and modulating cellular inflammation, it also enhances immune function by modulating CD8+ $T$ lymphocytes and natural killer (NK) cell activity (Tamura et al., 1999). There is a recent report that regulatory $T$ cells delay disease progression in AD-like pathology (Dansokho et al., 2016). Elderly patients with low vitamin B12 levels also have impaired antibody responses to pneumococcal vaccine (Fata, Herzlich, Schiffman, \& Ast, 1996).

Why not just measure serum B12 lab results and supplement as appropriate? Oxidative stress and inflammation, frequently associated with diminished levels of the body's principal antioxidant, glutathione, can impair serum B12 accuracy (Solomon, 2015). Which implies both aging and many psychiatric disorders may be associated with this issue. While there is no problem about the accuracy or importance of low serum B12 readings, the literature suggests that oral or parenteral supplementation to address this problem with a nonfunctional form of B12 under conditions of oxidative stress may or may not increase levels of the functional forms. Rietsaema (2014) describes the unexpected reversal of dementia in an 83-year-old woman after substituting Methyl-B12 for a non-functional form. McCaddon (2006) describes similar benefits in eight cases of mild cognitive impairment after nonfunctional forms had no effect by administering the glutathione enhancing supplement nacetylcysteine. The separate benefits of Methyl-B12 and Adeno-B12 supplementation will be discussed as well as oral glutathione or its amino acid precursors (Sekhar et al., 2011), along with some other complementary supplements for which there is significant evidence in the literature for improving brain function.

\section{References}

Dansokho, C., Ait Ahmed, D., Aid, S., Toly-Ndour, C., Chaigneau, T., Calle, V., ... Dorothée, G. (2016). Regulatory T cells delay disease progression in Alzheimer-like pathology. Brain, 139(4), 1237-1251. http://dx.doi.org/10.1093/brain/awv408

Fata, F. T., Herzlich, B. C., Schiffman, G., \& Ast, A. L. (1996). Impaired antibody responses to pneumococcal polysaccharide in elderly patients with low serum vitamin B12 levels. Annals of Internal Medicine, 124(3), 299-304.

Itzhaki, R. F., Lathe, R., Balin, B. J., Ball, M. J., Bearer, E. L., Braak, H., ... Whittum-Hudson, J. A. (2016). Microbes and Alzheimer's Disease. Journal of Alzheimer's Disease, 51(4), 979-984. http://dx.doi.org/10.3233/JAD-160152

McCaddon, A. (2006). Homocysteine and cognitive impairment; a case series in a General Practice setting. Nutrition Journal, 5(1), 1. http://dx.doi.org/10.1186/1475-2891-5-6

Rietsema, W. J. (2014). Unexpected recovery of moderate cognitive impairment on treatment with oral methylcobalamin. Journal of the American Geriatrics Society, 62(8), 1611-1612. http://dx.doi.org/10.1111/jgs.12966

Sekhar, R. V., Patel, S. G., Guthikonda, A. P., Reid, M., Balasubramanyam, A., Taffet, G. E., \& Jahoor, F. (2011). Deficient synthesis of glutathione underlies oxidative stress in aging and can be corrected by dietary cysteine and glycine supplementation. The American Journal of Clinical Nutrition, 94(3), 847-853. http://dx.doi.org/10.3945/ajcn.110.003483

Solomon, L. R. (2015). Functional cobalamin (vitamin B12) deficiency: Role of advanced age and disorders associated with increased oxidative stress. European Journal of Clinical Nutrition, 69(6), 687-692. http://dx.doi.org/10.1038 lejcn.2014.272

Tamura, J., Kubota, K., Murakami, H., Sawamura, M., Matsushima, T., Tamura, T., ... Naruse, T. (1999). Immunomodulation by vitamin B12: augmentation of CD8+ T lymphocytes and natural killer (NK) cell activity in vitamin B12-deficient patients by methyl-B12 treatment. Clinical \& Experimental Immunology, 116(1), 28-32.

Zhang, Y., Hodgson, N. W., Trivedi, M. S., Abdolmaleky, H. M., Fournier, M., Cuenod, M., ... Deth, R. C. (2015). Decreased Brain Levels of Vitamin B12 in Aging, Autism and Schizophrenia. PloS One, 11(1), e0146797. http://dx.doi.org /10.1371/journal.pone. 0146797 
What the Sham Is Going On? Redefining Attention Deficit/Hyperactivity Disorder (ADHD) and the Inherent Problems with Neurofeedlback Sham (Placebo-Controlled) Protocols in an Operant Conditioning Model Rex Cannon ${ }^{1}$ and Spencer Carroll ${ }^{2}$

${ }^{1}$ Neural Potential, LLC, Lake Worth, Florida, USA

${ }^{2}$ Knoxville Neurofeedback group, Knoxville, Tennessee, USA

There have been scarce advances in the uncovering of the etiology of Attention-Deficit/Hyperactivity Disorder (ADHD) over the past 30 years, despite advances in neuroimaging and neurophysiological methodologies. However, the amount of data accrued is extensive, yet an integrative model has yet to be constructed with clarity and standardization. In any type of problem in which a solution is evasive the primary lack of clarity and integration may be attributed to the operational operant definition given to the topic under investigation, as opposed to the methods used to investigate and treat the particular issue. ADHD is the most commonly diagnosed disorder in children and is projected to affect $5 \%$ to $7 \%$ of children worldwide and often continue on into adolescence and adulthood causing moderate difficulties for individuals across numerous adaptive contexts (Polanczyk, de Lima, Horta, Biederman, \& Rohde, 2007). Importantly, recent data indicate there has been no increase in the prevalence rate of ADHD worldwide when tightly controlled analytics are used. This does not account for analytic methods or diagnostic criteria and variability (Polanczyk, Willcutt, Salum, Kieling, \& Rohde, 2014). Additional problems exist in the accurate diagnosis of a "pure" ADHD sample since the comorbidity rate has been estimated to be as high as $80 \%$ (Pritchard, Nigro, Jacobson, \& Mahone, 2012) and variable cases of ADHD may also classify with up to five comorbid psychiatric diagnoses. Additionally, ADHD as a single diagnostic indicator occurs in less than $20 \%$ of the cases, or even less (Barkley \& Brown, 2008; Yaryura-Tobias, Rabinowitz, \& Neziroglu, 2003). There has been an increasing discourse over neurofeedback techniques and outcomes using sham/placebo-controlled methods yet the aforementioned difficulties remain everpresent (Arns, de Ridder, Strehl, Breteler, \& Coenen, 2009; Gevensleben et al., 2014; Guez et al., 2015; Hale et al., 2014; Lenartowicz \& Loo, 2014; Loo, Lenartowicz, \& Makeig, 2015; Micoulaud-Franchi et al., 2014; Polanczyk et al., 2007; Pritchard et al., 2012; Steiner, Frenette, Rene, Brennan, \& Perrin, 2014; van Dongen-Boomsma, Vollebregt, SlaatsWillemse, \& Buitelaar, 2013; Vollebregt, van Dongen-Boomsma, Buitelaar, \& Slaats-Willemse,
2013). Current problems, diagnostic issues, and recommendations for a concise, standard set of metrics and interventions will be presented and discussed.

\section{References}

Arns, M., de Ridder, S., Strehl, U., Breteler, M., \& Coenen, A. (2009). Efficacy of neurofeedback treatment in ADHD: The effects on inattention, impulsivity and hyperactivity: A metaanalysis. Clinical EEG and Neuroscience, 40(3), 180-189.

Barkley, R. A., \& Brown, T. E. (2008). Unrecognized attentiondeficit/hyperactivity disorder in adults presenting with other psychiatric disorders. CNS Spectrums, 13(11), 977-984. http://dx.doi.org/10.1017/S1092852900014036

Gevensleben, H., Albrecht, B., Lutcke, H., Auer, T., Dewiputri, W. I., Schweizer, R., ... Rothenberger, A. (2014). Neurofeedback of slow cortical potentials: Neural mechanisms and feasibility of a placebo-controlled design in healthy adults. Frontiers in Human Neuroscience, 8, 990. http://dx.doi.org/10.3389 /fnhum.2014.00990

Guez, J., Rogel, A., Getter, N., Keha, E., Cohen, T., Amor, T., ... Todder, D. (2015). Influence of electroencephalography neurofeedback training on episodic memory: A randomized, sham-controlled, double-blind study. Memory, 23(5), 683694. http://dx.doi.org/10.1080/09658211.2014.921713

Hale, T. S., Kane, A. M., Tung, K. L., Kaminsky, O., McGough, J. J., Hanada, G., \& Loo, S. K. (2014). Abnormal parietal brain function in ADHD: Replication and extension of previous EEG beta asymmetry findings. Frontiers in Psychiatry, 5, 87 http://dx.doi.org/10.3389/fpsyt.2014.00087

Lenartowicz, A., \& Loo, S. K. (2014). Use of EEG to diagnose ADHD. Current Psychiatry Reports, 16(11), 498. http://dx.doi.org/10.1007/s11920-014-0498-0

Loo, S. K., Lenartowicz, A., \& Makeig, S. (2015). Research review: Use of EEG biomarkers in child psychiatry research Current state and future directions. Journal of Child Psychology and Psychiatry, 57(1) 4-17. http://dx.doi.org /10.1111/jcpp.12435

Micoulaud-Franchi, J. A., Geoffroy, P. A., Fond, G., Lopez, R., Bioulac, S., \& Philip, P. (2014). EEG neurofeedback treatments in children with ADHD: An updated meta-analysis of randomized controlled trials. Frontiers in Human Neuroscience, $\quad 8, \quad 906 . \quad$ http://dx.doi.org/10.3389 /fnhum.2014.00906

Polanczyk, G., de Lima, M. S., Horta, B. L., Biederman, J., \& Rohde, L. A. (2007). The worldwide prevalence of ADHD: a systematic review and metaregression analysis. The American Journal of Psychiatry, 164(6), 942-948. http://dx.doi.org/10.1176/ajp.2007.164.6.942

Polanczyk, G. V., Willcutt, E. G., Salum, G. A., Kieling, C., \& Rohde, L. A. (2014). ADHD prevalence estimates across three decades: An updated systematic review and metaregression analysis. International Journal of Epidemiology, 43(2), 434-442.

Pritchard, A. E., Nigro, C. A., Jacobson, L. A., \& Mahone, E. M. (2012). The role of neuropsychological assessment in the functional outcomes of children with ADHD. Neuropsychology Review, 22(1), 54-68. http://dx.doi.org/10.1007/s11065-0119185-7

Steiner, N. J., Frenette, E. C., Rene, K. M., Brennan, R. T., \& Perrin, E. C. (2014). In-school neurofeedback training for ADHD: Sustained improvements from a randomized control trial. Pediatrics, 133(3), 483-492. http://dx.doi.org/10.1542 /peds.2013-2059

Van Dongen-Boomsma, M., Vollebregt, M. A., Slaats-Willemse, D., \& Buitelaar, J. K. (2013). A randomized placebo-controlled trial of electroencephalographic (EEG) neurofeedback in 
children with attention-deficit/hyperactivity disorder. Journal of Clinical Psychiatry, 74(8), 821-827. http://dx.doi.org/10.4088 IJCP.12m08321

Vollebregt, M. A., van Dongen-Boomsma, M., Buitelaar, J. K., \& Slaats-Willemse, D. (2013). Does EEG-neurofeedback improve neurocognitive functioning in children with attentiondeficit/hyperactivity disorder? A systematic review and a double-blind placebo-controlled study. Journal of Child Psychology and Psychiatry, 55(5), 460-472. http://dx.doi.org /10.1111/jcpp.12143

Yaryura-Tobias, J. A., Rabinowitz, D. C., \& Neziroglu, F. (2003). Possible basal ganglia pathology in children with complex symptoms. Journal of Clinical Psychiatry, 64(12), 1495-1501.

\section{Domestic Violence and Brain Injury: A New} Approach. Using Neurofeedback in a Domestic Violence Program

Joshua Brown, Huda Shaikh, and Peggy Wright

Fort Bend County Women's Center, Richmond, Texas, USA

In recent years, general awareness of traumatic brain injury (TBI) has increased substantially. A significant reason for this may be the media's coverage linking increased TBI diagnoses and symptoms with combat veterans and athletes. Despite this increased awareness, one population is still largely overlooked in terms of screening and treatment of TBI. Survivors of domestic violence (otherwise known as Intimate Partner Violence or IPV) have been shown to have a high likelihood of head and neck injuries due to violence. In light of the seemingly high correlation between IPV and TBI, the Fort Bend Women's Center (FBWC) began a program to screen for and address TBI in this population. As a result of preliminary screening, it was determined that well over half of current FBWC adult clients screened positive for a potential brain injury. Recognizing that TBI symptoms could adversely affect an IPV survivor's self-sufficiency and safety, FBWC sought out effective interventions. FBWC discovered neurofeedback and the promising evidence of its effectiveness in addressing TBI symptoms. FBWC launched a pilot program to address TBI-related symptoms using qEEG-guided neurofeedback as a cornerstone. Utilizing both quantitative and qualitative pre/post measures, FBWC sought to determine the extent to which neurofeedback could remediate TBI-related symptoms experienced by survivors of IPV. To determine the impact of the neurofeedback training, FBWC's program uses standardized written pre/post measurements for assessing overall disability, psychiatric symptoms, depression, anxiety, posttraumatic stress, and substance use. The program also utilizes pre/post qEEG recordings and pre/post videotaped interviews for further evidence of behavioral change. Early results are promising and indicate significant positive changes in scores for disability, depression, anxiety, posttraumatic stress, and substance use. Quantitative EEG comparisons reveal significant changes toward the norm, and videotaped interviews signify noticeable qualitative changes, including changes in grooming and dispositional affect. As of March 2016, the program has recruited 68 participants who have completed at least some of the requirements. Nine participants have completed all pre/post measures and a complete round of individualized neurofeedback training (average $=42$ sessions). Average written assessment results for those who have completed the program include:

- $22 \%$ reduction in disability scores on the World Health Organization Disability Assessment Schedule

- $42 \%$ reduction in scores on the DSM-5 SelfRated Level 1 Cross-Cutting Symptom Measure - Adult

- $57 \%$ reduction in scores on the DSM-5 Severity Measure for Depression - Adult

- $49 \%$ reduction in scores on the DSM-5 Severity Measure for Generalized Anxiety Disorder - Adult

- $45 \%$ reduction in scores on the DSM-5 Severity of Posttraumatic Stress Symptoms - Adult

- $100 \%$ reduction in scores on the DSM-5 Level 2- Substance Use - Adult (only two participants reported substance use)

\section{References}

Arosarena, O. A., Fritsch, T. A., Hsueh, Y., Aynehchi, B., \& Haug, R. (2009). Maxillofacial injuries and violence against women. Archives of Facial Plastic Surgery, 11(1), 48-52. http://dx.doi.org/10.1001/archfacial.2008.507

Dawodu, S. T. (2015, September 22). Traumatic Brain Injury (TBI) - Definition and Pathophysiology. Medscape. Retrieved March 31, 2016, from http://emedicine.medscape.com /article/326510-overview - showall

DoD Worldwide Numbers for TBI. Defense and Veterans Brain Injury Center. Retrieved March 31, 2016 from http://dvbic.dcoe.mil/dod-worldwide-numbers-tbi

Hoofien, D., Gilboa, A., Vakil, E., \& Donovick, P. J. (2001). Traumatic Brain Injury (TBI) 10-20 years later: A comprehensive outcome study of psychiatric symptomatology, cognitive abilities and psychosocial functioning. Brain Injury, 15(3), 189-209. http://dx.doi.org /10.1080/026990501300005659

Injury Prevention \& Control: Traumatic Brain Injury \& Concussion. Centers for Disease Control and Prevention, Division of Unintentional Injury Prevention. Retrieved March 31, 2016 from http://www.cdc.gov/traumaticbraininjury /data/index.html

Kwako, L. E., Glass, N., Campbell, J., Melvin, K. C., Barr, T., \& Gill, J. M. (2011). Traumatic brain injury in intimate partner violence: A critical review of outcomes and mechanisms. Trauma, Violence, \& Abuse, 12(3), 115-126. http://dx.doi.org $/ 10.1177 / 1524838011404251$ 
Murray, C. E., Lundgren, K., Olsen, L. N., \& Hunnicutt, G. (2016). Practice update: What professionals who are not brain injury specialists need to know about intimate partner violencerelated traumatic brain injury. Trauma, Violence, \& Abuse, 17(3), $\quad$ 298-305. http://dx.doi.org/10.1177 $/ 1524838015584364$

Picard, M., Scarisbrick, D., Paluck, R. (1991). HELPS: A brief screening devic for traumatic brain injury. New York, NY: Comprehensive Regional TBI Rehabilitation Center.

Traumatic Brain Injury and Domestic Violence: Understanding the Intersections. National Online Resource Center on Violence Against Women. Retrieved March 31, 2016, from http://vawnet.org/sc/traumatic-brain-injury-and-domesticviolence-understanding-intersections

Traumatic Brain Injury Model Systems. Model Systems Knowledge Translation Center. Retrieved March 31, 2016, from http://www.msktc.org/tbi

Valera, E. M., \& Berenbaum, H. (2003). Brain injury in battered women. Journal of Consulting and Clinical Psychology, 71(4), 797-804.

\section{Exploring the Impact of Single-Channel,} Bivariate and Multivariate Coherence Training on mu Suppression Deficits in Autism

\section{Spectrum Disorders}

\section{Janease Traylor and Robert Coben}

Integrated Neuroscience Services, Fayetteville, Arkansas, USA

Autism spectrum disorder (ASD) can be described as a "group of developmental disabilities that can cause significant social, communication, and behavioral challenges." The epidemiological data presented by the CDC reported that 1 in 68 children are currently diagnosed with ASD in the United States (CDC, 2016). The CDC has noted an increase in the prevalence of ASD since the 1990s, making effective treatment an important part of the national health conversation. A review of the scientific literature yielded studies that indicated connectivity in the brain to have a major impact on autistic symptoms and indicated neurofeedback therapy to be an effective treatment for ASD (Coben \& Hudspeth, 2006; Coben, Mohammad-Rezazadeh, \& Cannon, 2014); however, sufficient literature was not found to explore differing modalities of neurofeedback treatment. Research, by Pineda, showed ASD symptomology to have ties with mirror neuron systems and mu rhythm suppression deficits (Pineda, 2005). One particular study indicated proof that coherence training is more effective in treatment than bipolar training, supporting the idea that the problems in ASD are, at least in part, also related to challenges in coherence (Coben \& Hudspeth, 2006).

Methods. A total of 42 individuals diagnosed on the autism spectrum, were randomly assigned to three treatment groups. They received treatment including bipolar power training, two-channel coherence training, and four-channel multivariate coherence training. Changes in mu rhythm, mu rhythm suppression, power and coherence, and general autistic symptoms and various aspects of social skills will serve as the dependent variables. We will create a session score that appreciates coherence changes globally per session. Analysis will include the use of SPSS software for a MANOVA analysis. It will also include the use of NRep software suite to measure global changes in power and coherence.

Assessments. Quantitative electroencephalogram studies were performed pre- and posttreatment, followed by parent report measures of the Social Responsiveness Scale-Second Edition (SRS-2; Constantino, 2012) and Autism Treatment Evaluation Checklist (ATEC), a parent-rated scale (Rimland \& Edelson, 1999). QEEG data was then analyzed with the NeuroRep software suite. ASD symptomology will be rated using the ATEC and parent rated social skills will be appreciated using the SRS-2.

Results: Results of comparison of the first two treatment groups, 2 channel coherence training and bipolar power training, done through statistical analysis using ANOVAs, revealed significant differences with 2 channel coherence training being more effective in lessening mu suppression deficits. Full statistical analysis and discussion of the current data will be presented, using ANOVA and post hoc statistical tests, to evaluate changes in parent reported symptoms, mu rhythm, mu rhythm suppression, and coherence. Our hypothesis that 4 channel multivariate coherence training is more beneficial than bipolar power training and 2 channel coherence training in lessening deficits in social interaction and mu suppression deficits in individuals with ASD diagnoses. Discussion/Conclusion: We hope to help expand the growing knowledge base with this study to further explore the efficacy of different treatment modalities on this group of disorders to help reduce symptoms in individuals with ASD.

\section{References}

Centers for Disease Control and Prevention. (2016). Autism Spectrum Disorder (ASD). Retrieved from http://www.cdc.gov /ncbddd/autism/index.html

Coben, R., \& Hudspeth, W. (2006). Mu-like rhythms in autistic spectrum disorder: EEG analyses and neurofeedback outcome. Presented at INSR Conference, Atlanta, GA.

Coben, R., Mohammad-Rezazadeh, I., Cannon, R. L. (2014). Using quantitative and analytic EEG methods in the understanding of connectivity in autism spectrum disorders: A theory of mixed over- and under-connectivity. Frontiers in 
Human Neuroscience, 8, 45. http://dx.doi.org/10.3389 /fnhum.2014.00045

Coben, R., Sherlin, L., Hudspeth, W. J., McKeon, K., \& Ricca, R. (2014). Connectivity-guided EEG biofeedback for autism spectrum disorder: Evidence of neurophysiological changes. NeuroRegulation, 1(2), 109-130. http://dx.doi.org/10.15540 Inr.1.2.109

Constantino, J. N., \& Gruber, C. P. (2012). Social Responsiveness Scale (2nd ed.). Los Angeles, CA: Western Psychological Services.

Pineda, J. A. (2005). The functional significance of mu rhythms: Translating from "seeing" and "hearing" into "doing." Brain Research Reviews, 50(1), 57-68. http://dx.doi.org/10.1016 /j.brainresrev.2005.04.005

Rimland B., \& Edelson, M. (1999). Autism Treatment Evaluation Checklist. Autism Research Institute. 4812 Adams Avenue, San Diego, CA 92116. Retrieved from https://www.autismeval.com/ari-atec/report1.html

\section{Does Neurofeedback Reduce the Incidence of Behavioral Incidents in an Adolescent Residential Treatment Facility J. Michael Griffin \\ Commonwealth Behavioral Healthcare, LLC, Emporia, Virginia, USA}

Adolescents in long-term residential facilities often have histories of abuse and neglect as well as family histories of mental illness. Often these youths have received years of outpatient treatment, multiple inpatient psychiatric hospitalizations in acute care facilities, foster placements, and multiple behavioral health residential admissions. Multiple treatment modalities have conventionally been used, including counseling, psychopharmacology, recreational therapy, therapeutic horticulture, equestrian therapy, and others. Despite these interventions, significant acting out behaviors may persist to a degree in which their families and professionals continue to look for more effective means of treatment. A simple Google internet search for "residential treatment programs for adolescents" returns a number of hits, indicating the inclusion of neurofeedback in these programs is fairly commonplace. Yet, a Medline search fails to find efficacy studies supporting the practice in neurofeedback in these facilities, while a discussion with administrators of these programs yield the strong opinion that they are beneficial adjunctive treatment, reducing the frequency and intensity of adverse behavioral events, including aggression to staff, resident-to-resident aggression, stealing, destruction of property, and so on. The current study, performed at Jackson-Feild Behavioral Health Services in Jarratt, VA, seeks to determine whether neurofeedback may be an effective adjunctive treatment in residential behavioral health facilities. Adolescents 13 to 18 years of age were selected by their treatment team for neurofeedback due to continued acting out in their cottages or elsewhere at the facility. Diagnoses include disruptive mood dysregulation disorder, bipolar disorder, obsessive-compulsive disorder, posttraumatic stress disorder, attentiondeficit/hyperactivity disorder, oppositional-defiant disorder, conduct disorder, and (emerging) borderline personality disorder. The literature contains numerous peer-reviewed papers describing the benefit of neurofeedback in addressing these issues. All individuals in the study continued to receive psychopharmacology in the form of antidepressants, mood stabilizers, stimulant medications, antihypertensives, and so on, as determined appropriate by their psychiatrist. They also attended the school located on the campus, attend groups and individual counseling, as scheduled by their treatment teams. The outcome measure used in this study was simply the number of incident reports for each adolescent in the study, preneurofeedback and postneurofeedback. After compiling these data, descriptive statistic and nonparametric methods were used to analyze the findings.

\section{References}

Arns, M., Heinrich, H., \& Strehl, U. (2014). Evaluation of neurofeedback in ADHD: The long and winding road. Biological Psychology, 95, 108-15. http://dx.doi.org/10.1016 /j.biopsycho.2013.11.013

Collura, T. F. (2014). Technical foundations of neurofeedback. New York, NY: Routledge.

Fisher, S. F. (2014). Neurofeedback in the treatment of developmental trauma. New York, NY: W.W. Norton \& Co.

Henriques, J. B., \& Davidson, R. J. (1991). Left frontal hypoactivation in depression. Journal of Abnormal Psychology, 100(4), 533-545.

Thompson, L., Thompson, M., Reid, A. (2010). Neurofeedback outcomes in clients with Asperger's syndrome. Applied Psychophysiology and Biofeedback, 35(1), 63-81. http://dx.doi.org/10.1007/s10484-009-9120-3

Walker, J. (2013). QEEG-guided neurofeedback for anger/anger control disorder. Journal of Neurotherapy, 17(1), 88-92. http://dx.doi.org/10.1080/10874208.2012.705767

\section{The Effects of Side Effects}

Ainat Rogel, Khaled Nasser, and Elizabeth Southwell

The Trauma Center at JRI, Brookline, Massachusetts, USA

There is a preponderance of evidence demonstrating neurofeedback training (NFT) as an effective therapeutic intervention for various disorders such as attention-deficit/hyperactivity disorder (ADHD; Arns, de Ridder, Strehl, Breteler, \& Coenen, 2009; Beauregard \& Levesque, 2006; Lubar, 2003) and epilepsy (Sterman \& Egner, 2006; Tan et al., 2009). As with therapeutic interventions, there are adverse side effects. Although side effects were reported since the early days of NFT (e.g., 
Hammond, Stockdale, Hoffman, Ayers, \& Nash, 2001; Lubar \& Shouse, 1976), there are only a few rigorous studies (Rogel et. al, 2015). This presentation tackles the effects of side effects by focusing specifically on their prevalence, severity, detection, and treatment.

Adverse side effects may be prevalent. In a study of 30 young healthy adults, $70 \%$ reported 78 side effects. Most were mild and transient, for example, headaches, fatigue, and mood swings (Rogel et al., 2015). Adverse side effects can be divided into nonspecific, associated with the training in general, and specific, associated with the particular protocol (Matthews, 2007; Ochs, 2007; Rogel et al., 2015). Applying inappropriate NFT protocols has been found to be a major cause while certain protocols are more likely to cause specific side effects, for example, increasing power (Hammond \& Kirk, 2008; Lubar et al., 1981; Whitsett, Lubar, Holder, Pamplin, \& Shabsin, 1982). Although many side effects are transient and will be resolved on their own (e.g., headaches, fatigue, irritability, or long-term pain; Hammond \& Kirk, 2008; Hammond et al., 2001), some are severe and persistent, for example, memory problems (Todder, Levine, Dwolatzky, \& Kaplan, 2010), depression, seizures, depression, manic attacks. Adjusting the protocol, augmenting treatment with additional protocols, or terminating a protocol often eliminate side effects (Hammond \& Kirk, 2008). We focus on assessment and effective elimination strategies in an ongoing study. Our unpublished data collected from 18 children, ages $6-13$, who suffered from at least two stressors, have shown that $88 \%$ of participants reported at least one side effect. Moreover, 50\% reported at least five. Anxiety, increase of energy level, and sleep disturbance were common. Severity varied from tiredness to dizziness, bed wetting, suicidal ideation, and worsening tics. All were addressed and resolved. We focus on assessment and effective elimination strategies in an ongoing study. Currently we are unaware of standard detection tools. Although it is common to track the symptoms that the protocol is meant to address, we recommend tracking changes over a wide range of known effects. Clients may not be obviously associating adverse effects with the NFT, therefore, we have found it beneficial to not only ask the client of symptoms but also to complete a questionnaire. In addition, we recommend that NFB trainees sign a consent form, similar to that involved in medical procedures. Justifiably, the scientific community feels suspicious of an intervention claiming only positive outcomes. Therefore, the study of side effects is important for NFT in order to be accepted as a valid intervention. Detecting and addressing side effects cannot only improve the outcome but also be an ethical obligation of the NFT practitioners.

\section{References}

Arns, M., de Ridder, S., Strehl, U., Breteler, M., \& Coenen, A. (2009). Efficacy of neurofeedback treatment in ADHD: The effects on inattention, impulsivity and hyperactivity: A metaanalysis. Clinical EEG and Neuroscience, 40(3), 180-189. http://dx.doi.org/10.1177/ 155005940904000311

Beauregard, M., \& Levesque, J. (2006). Functional magnetic resonance imaging investigation of the effects of neurofeedback training on the neural bases of selective attention and response inhibition in children with attentiondeficit/hyperactivity disorder. Applied Psychophysiology and Biofeedback, 31(1), 3-20. http://dx.doi.org/10.1007/s10484006-9001-y

Hammond, D. C., \& Kirk, L. (2008). First, do no harm: Adverse effects and the need for practice standards in neurofeedback. Journal of Neurotherapy, 12(1), 79-88. http://dx.doi.org /10.1080/10874200802219947

Hammond, D. C. (2011). What is neurofeedback: An update. Journal of Neurotherapy, 15(4), 305-336. http://dx.doi.org /10.1080/10874208.2011.623090

Hammond, D. C., Stockdale, S., Hoffman, D., Ayers, M. E., \& Nash, J. (2001). Adverse reactions and potential iatrogenic effects in neurofeedback training. Journal of Neurotherapy, 4(4), 57-69. http://dx.doi.org/10.1300/J184v04n04_09

Lubar, J. F. (2003). Neurofeedback for the management of attention-deficit/hyperactivity disorders. In M. S. Schwartz \& F. Andrasik (Eds.), Biofeedback: A practitioner's guide (3rd ed., pp. 409-437). New York, NY: The Guilford Press.

Lubar, J. F., Shabsin, H. S., Natelson, S. E., Holder, G. S., Whitsett, S. F., Pamplin, W. E., \& Krulikowski, D. I. (1981). EEG operant conditioning in intractable epileptics. Archives of Neurology, 38(11), 700-704.

Lubar, J. F., \& Shouse, M. N. (1976). EEG and behavioral changes in a hyperkinetic child concurrent with training of the sensorimotor rhythm (SMR): A preliminary report. Biofeedback and Self-Regulation, 1(3), 293-306.

Matthews, T. V. (2007). Neurofeedback overtraining and the vulnerable patient. Journal of Neurotherapy, 11(3), 63-66. http://dx.doi.org/10.1080/10874200802126290

Ochs, L. (2007). Comment on "neurofeedback overtraining and the vulnerable patient." Journal of Neurotherapy, 11(3), 6771. http://dx.doi.org/10.1080/10874200802126357

Rogel, A., Guez, J., Getter, N., Keha, E., Cohen, T., Amor, T., \& Todder, D. (2015). Transient adverse side effects during neurofeedback training: A randomized, sham-controlled, double blind study. Applied Psychophysiology and Biofeedback, 40(3), 209-218. http://dx.doi.org/10.1007 /s10484-015-9289-6

Sterman, M. B., \& Egner, T. (2006). Foundation and practice of neurofeedback for the treatment of epilepsy. Applied Psychophysiology and Biofeedback, 31(1), 21-35. http://dx.doi.org/10.1007/s10484-006-9002-x

Tan, G., Thornby, J., Hammond, D. C., Strehl, U., Canady, B., Arnemann, K., \& Kaiser, D. A. (2009). Meta-analysis of EEG biofeedback in treating epilepsy. Clinical EEG and Neuroscience, $\quad 40(3), \quad 173-179 . \quad \mathrm{http}: / / \mathrm{dx}$.doi.org/10.1177 $/ 155005940904000310$

Todder, D., Levine, J., Dwolatzky, T., \& Kaplan, Z. (2010). Case report: Impaired memory and disorientation induced by delta band down-training over the temporal brain regions by neurofeedback treatment. Journal of Neurotherapy, 14(2), 153-155. http://dx.doi.org/10.1080/10874201003766785

Whitsett, S. F., Lubar, J. F., Holder, G. S., Pamplin, W. E., \& Shabsin, H. S. (1982). A double-blind investigation of the 
relationship between seizure activity and the sleep EEG

following EEG biofeedback training. Biofeedback and SelfRegulation, 7(2), 193-209.
Received: November 27, 2016

Accepted: November 27, 2016

Published: December 8, 2016 